US Army Corps of Engineers ${ }_{\circledast}$

Engineer Research and

Development Center

\title{
Investigation into Laboratory Bathymetric Measurement Techniques
}

Brian C. McFall and Guido Wolters

April 2020

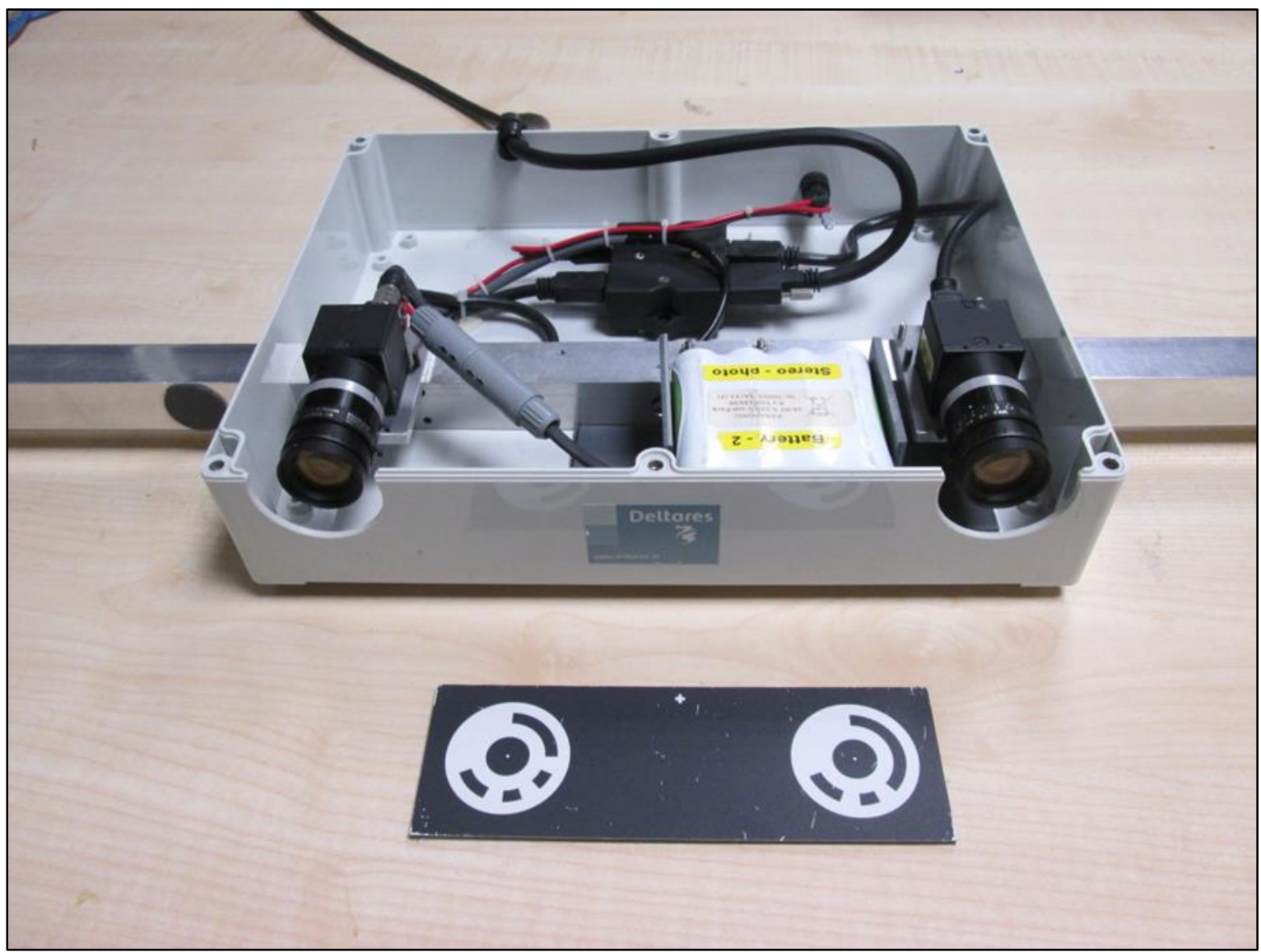


The US Army Engineer Research and Development Center (ERDC) solves the nation's toughest engineering and environmental challenges. ERDC develops innovative solutions in civil and military engineering, geospatial sciences, water resources, and environmental sciences for the Army, the Department of Defense, civilian agencies, and our nation's public good. Find out more at www.erdc.usace.army.mil.

To search for other technical reports published by ERDC, visit the ERDC online library at http://acwc.sdp.sirsi.net/client/default. 


\title{
Investigation into Laboratory Bathymetric Measurement Techniques
}

\author{
Brian C. McFall \\ Coastal and Hydraulics Laboratory \\ US Army Engineer Research and Development Center \\ 3909 Halls Ferry Road \\ Vicksburg, MS 39180-6199 \\ Guido Wolters \\ Deltares \\ Rotterdamsweg 185 \\ 2629HD, Delft, The Netherlands
}

Final report

Approved for public release; distribution is unlimited.

\author{
Prepared for DASA DEC DDODDAC W81MR5 \\ OA-22 HQ \\ Arlington, VA 22202 \\ Under MIPR 11101100
}




\section{Abstract}

There is no universally accepted way to accurately and efficiently measure bathymetry in laboratory hydraulic models. Remote sensing techniques can measure bathymetry without making contact with the model, and some remote sensing techniques can measure the bathymetry in laboratory models without draining the water. The four categories of remote sensing technology investigated in this report are echo sounding technology, laser technology, image processing technology, and radar technology. The technology of each category has strengths and limitations, but can be used in the laboratory to measure bathymetry. Echo sounding technology works well in environments with suspended sediment, but the accuracy is reduced by large beam footprints. Laser technology does not perform as well with suspended sediment but can provide high-accuracy bathymetric measurements. Stereophotography, discussed in the image processing technology section, requires optically clear water and can provide very accurate bathymetric mapping. Radar technology can be very helpful when sub-bottom stratigraphy is important. Technology from each of the categories has been scaled for field application to measure bathymetry and submerged coastal structures.

DISCLAIMER: The contents of this report are not to be used for advertising, publication, or promotional purposes. Citation of trade names does not constitute an official endorsement or approval of the use of such commercial products. All product names and trademarks cited are the property of their respective owners. The findings of this report are not to be construed as an official Department of the Army position unless so designated by other authorized documents. 


\section{Contents}

Abstract.................................................................................................................. if

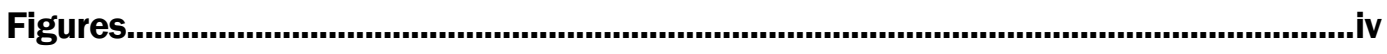

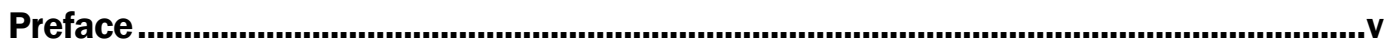

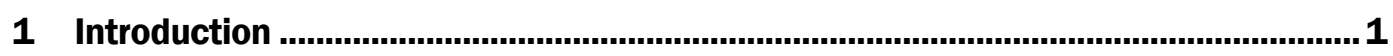

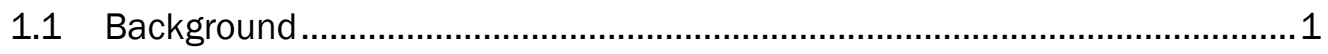

1.2 Objective ............................................................................................ 1

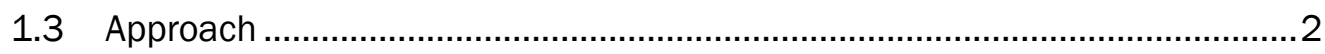

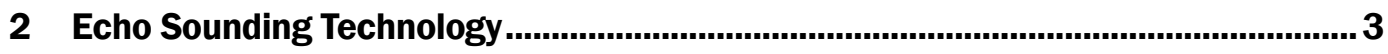

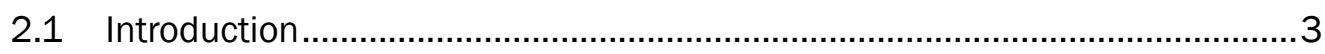

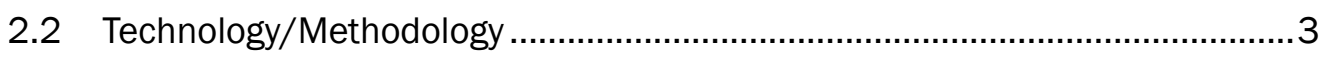

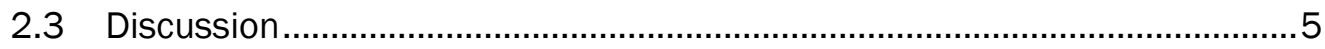

3 Laser Technology ........................................................................................................ 7

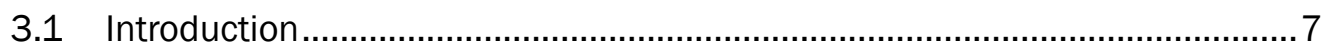

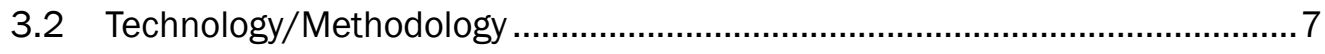

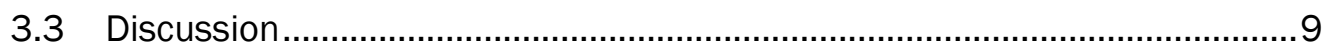

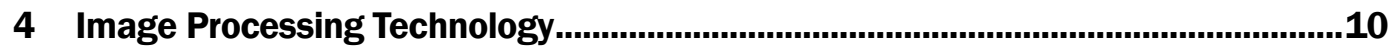

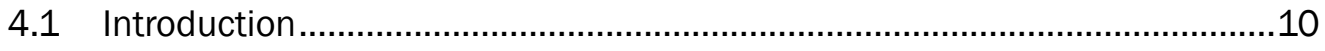

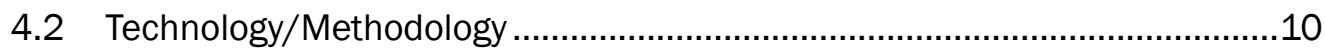

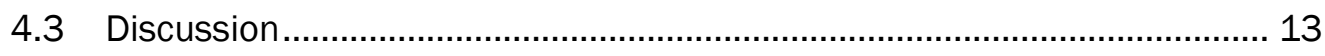

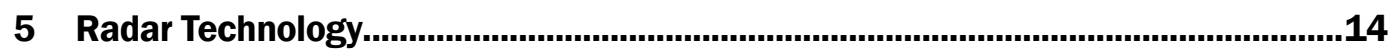

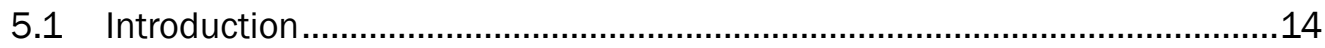

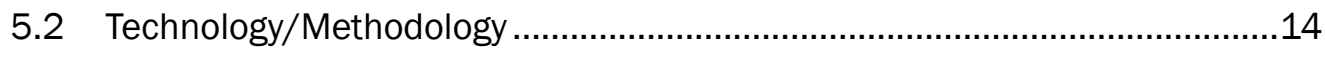

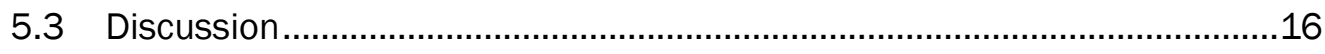

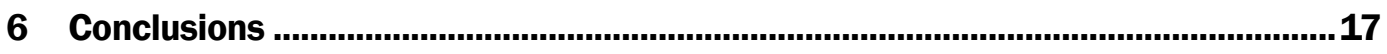

References.............................................................................................................19

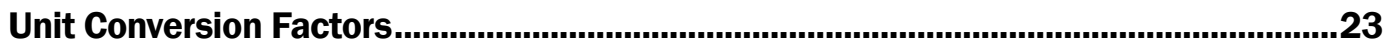

Acronyms and Abbreviations ................................................................................24

Report Documentation Page 


\section{Figures}

Figure 1. MTA with 32 transducers used by McFall (2014) to measure the bathymetry of scaled landslide deposits..

Figure 2. Stereophotography camera system and typical target used by Raaijmakers et al. (2012). The distance between the cameras is known, and the cameras are synchronized. 


\section{Preface}

This study was prepared for DASA DEC DDODDAC W81MR5 OA-22, under MIPR 11101100.

The study was conducted while the first author was at Deltares as part of a 1-year tour through the Engineer and Scientist Exchange Program (ESEP). The ESEP is a professional development exchange program that provides career-broadening work assignments for US military/government defense personnel in foreign defense establishments. The assignment is funded by the US Deputy Assistant Secretary of the Army, and research topics are supported by the Dutch Ministry of Defense.

Dr. Marcel van Gent was the Department Head of Coastal Structures and Waves, and Mr. Maarten Smits was the managing director of Deltares.

At the time of publication of this report, Ms. Lauren M. Dunkin was Chief of the Coastal Engineering Branch, and Dr. Jacqueline S. Pettway was Chief of the Navigation Division, Coastal and Hydraulics Laboratory (CHL), US Army Engineer Research and Development Center (ERDC). The Deputy Director of ERDC-CHL was Mr. Jeffrey R. Eckstein, and Dr. Ty V. Wamsley was the Director.

COL Teresa A. Schlosser was the Commander of ERDC, and the Director was Dr. David W. Pittman. 


\section{Introduction}

\subsection{Background}

Accurately and efficiently measuring the bathymetry of hydraulic physical models is a common problem world wide. As such, there is no universally accepted method to rapidly survey the bathymetry of movable bed studies using remote sensing techniques. This problem is applicable to hydraulic models in two-dimensional flumes and three-dimensional basins. Several large wave basins and flumes have historically used contact, wheeled profilers such as the Canal d'Investigació i Experimentació Marítima large wave flume at Universitat Politècnica de Catalunya, Barcelona (Baldock et al. 2011); the Grosser Wellenkanal wave flume in Hannover (Ciavola et al. 2011); Delta Flume at Deltares, Delft (Van Gent 2015); and the Large-scale Sediment Transport Facility in Vicksburg, MS (Smith et al. 2017a). These wheeled profilers can efficiently measure a bathymetric profile transect but can potentially modify the bathymetric profile being measured by making contact with the movable bed. Typically, several profile transects are measured when employing this technique, but the spatial resolution of the bathymetric measurements is limited.

In addition to wheeled profilers, bathymetry measurements in hydraulic physical models are commonly measured using a point survey method (Bryant and McFall 2016) or require draining of the model to scan the bathymetry with LIDAR (Smith et al. 2017b). Point measurements can be conducted with water in the basin or flume but may be time consuming, have limited spatial resolution, and can modify the bathymetry by physically contacting the model. Draining the basin and scanning a model with LIDAR produces high spatial resolution, but draining the basin can modify the bathymetry and is very time consuming. Additionally, analysis of terrestrial LIDAR point clouds can be very computationally expensive.

\subsection{Objective}

The objective of this study is to investigate various remote sensing techniques that could be used in a laboratory setting. 


\subsection{Approach}

Continued development of remote sensing techniques has led to highaccuracy, rapid bathymetric measurements. The remote sensing hardware and techniques investigated in this report fall into four categories:

1. Echo Sounding Technology

2. Laser Technology

3. Image Processing Technology

4. Radar Technology

Each of the categories will be investigated for utilization to accurately and efficiently measure submerged coastal structures and bathymetry in movable bed physical models.

Although the technologies will be primarily investigated for laboratory settings, the scaling of the methodology for field application will be considered. This can be very useful to assess submerged coastal structures and bathymetry for the US Department of Defense key strategic missions of Anti-Access/Area Denial, Humanitarian Aid and Disaster Relief, Joint Logistics Over The Shore, Austere Entry, and Expeditionary Maneuver. Novel methodologies to measure bathymetry directly support several of the Army Warfighting Challenges (AWFC) such as AWFC 2: Shape the Security Environment; AWFC 12: Conduct Joint Expeditionary Maneuver and Entry Operations; and AWFC 16: Set the Theater, Sustain Operations, and Maintain Freedom of Movement. Additionally, scaled methods described in this report can assist in the assessment of the submerged portions of ports and coastal facilities to support AWFC 6: Conduct Homeland Operations by assisting civil authorities in response to complex catastrophes. In addition to supporting the US Department of Defense, the use of remote sensing technology to measure bathymetry and submerged coastal structures can be equally beneficial to the Dutch Ministry of Defense to monitor evolving coastlines and submerged coastal structures. 


\section{Echo Sounding Technology}

\subsection{Introduction}

Echo sounding technology uses an acoustic transducer to transmit and receive acoustic energy. Echo sounding technology has been used for many years by vessels conducting hydrographic surveys. Additionally, echo sounding technology can be used to measure the water surface or the bathymetry using different instruments. Echo sounding devices used to measure the bathymetry are required to be submerged.

\subsection{Technology/Methodology}

Altimeter: An altimeter is an ultrasonic transducer that uses acoustic pulses to provide a point measurement between the sensor and the reflected surface. Altimeters are commonly used both in the field and in the laboratory and are required to keep the acoustic transducer in water to operate. The acoustic beam size (or spot size) is inversely proportional to the acoustic frequency (i.e., higher frequencies have a smaller spot size [Porter et al. 2014]), but higher frequencies attenuate faster in water with high suspended sediment concentrations (McGovern et al. 2012). Commercially available altimeters generally operate in the frequency range of $50 \mathrm{kHz}^{1}$ to $10 \mathrm{MHz}$ and can have an advertised vertical resolution of less than $1 \mathrm{~mm}$ (Coleman et al. 2003).

Altimeters have been used to profile bed ripples and monitor local bed morphology by either translating or rotating the altimeter (Dingler et al. 1977; Vincent and Osborne 1993; Greenwood et al. 1993; Jetté and Hanes 1997; Bell et al. 1998). The ripple profilers provide quantitative measurements of ripple wavelength and heights with an accuracy of $5 \mathrm{~mm}$ (Bell et al. 1998). The same techniques of sensor rotation or translation on an instrument arm can be used to profile transects of movable bed models in flumes or basins.

Acoustic Doppler velocimeter: Some acoustic Doppler velocimeters (ADVs) are equipped to measure bottom point measurements, such as the Nortek

\footnotetext{
1 For a full list of the spelled-out forms of the units of measure used in this document, please refer to US Government Publishing Office Style Manual, 31st ed. (Washington, DC: US Government Publishing Office, 2016), 248-52, https://www.govinfo.gov/content/pkg/GPO-STYLEMANUAL-2016/pdf/GPOSTYLEMANUAL-2016.pdf.
} 
Vectrino II (https://www.nortekgroup.com/). In addition to providing a point velocity measurement 40-70 mm below the probe, the Nortek Vectrino II can measure the bottom profile up to $2 \mathrm{~m}$ below the probe with an advertised accuracy of $0.5 \mathrm{~mm}$. The benefit of incorporating the bottom measurement with the point velocity measurement is to know how far above the bed the point velocity measurement is taken. The bed profile measurement was tested with settling mud in a laboratory by Traykovski et al. (2004). It was found that 1.0 $\mathrm{MHz}$ acoustic energy could penetrate, scatter off the bottom of the tank and then return to the ADV through thin $\left(5^{-10} \mathrm{~cm}\right)$ layers of recently deposited mud. The 1.0 $\mathrm{MHz}$ frequency was chosen because it has the lowest attenuation due to sediment. The Nortek Vectrino II operates with an acoustic frequency of $10 \mathrm{MHz}$. The higher acoustic frequency will have an improved bottom response to dense sand and gravel commonly used in movable bed models (Fugate and Friedrichs 2002).

Multiple transducer array (MTA): An MTA is an array of acoustic transducers that can be mounted in series to measure bathymetric profile and can be moved by an instrumentation arm or trolley to measure threedimensional bathymetric areas. The 32-transducer MTA shown in Figure 1 was successfully used in a laboratory setting to measure submarine landslide deposits in landslide generated tsunami experiments (Mohammed 2010; McFall 2014; McFall et al. 2018). Jetté and Hanes (1997) used a 37-transducer array and scanned a length of $45 \mathrm{~cm}$ with a vertical accuracy of $\sim 1 \mathrm{~mm}$ and $2 \mathrm{~cm}$ horizontal resolution. Similarly, Friedrich et al. (2005) conducted laboratory tests with a 31 transducer array operating at $5 \mathrm{MHz}$ and found it had an operating range of 3.6 to 100 $\mathrm{cm}$ and an accuracy of $\pm 1.00 \mathrm{~mm}$. Perkey and Wadman (2014) conducted laboratory tests with a 16 transducer array operating at $5 \mathrm{MHz}$ frequency. Bed elevation changes were measured with $<1 \mathrm{~mm}$ accuracy. The MTA has the advantage of measuring the bathymetry at several locations rather than a single point measurement. 
Figure 1. MTA with 32 transducers used by McFall (2014) to measure the bathymetry of scaled landslide deposits.

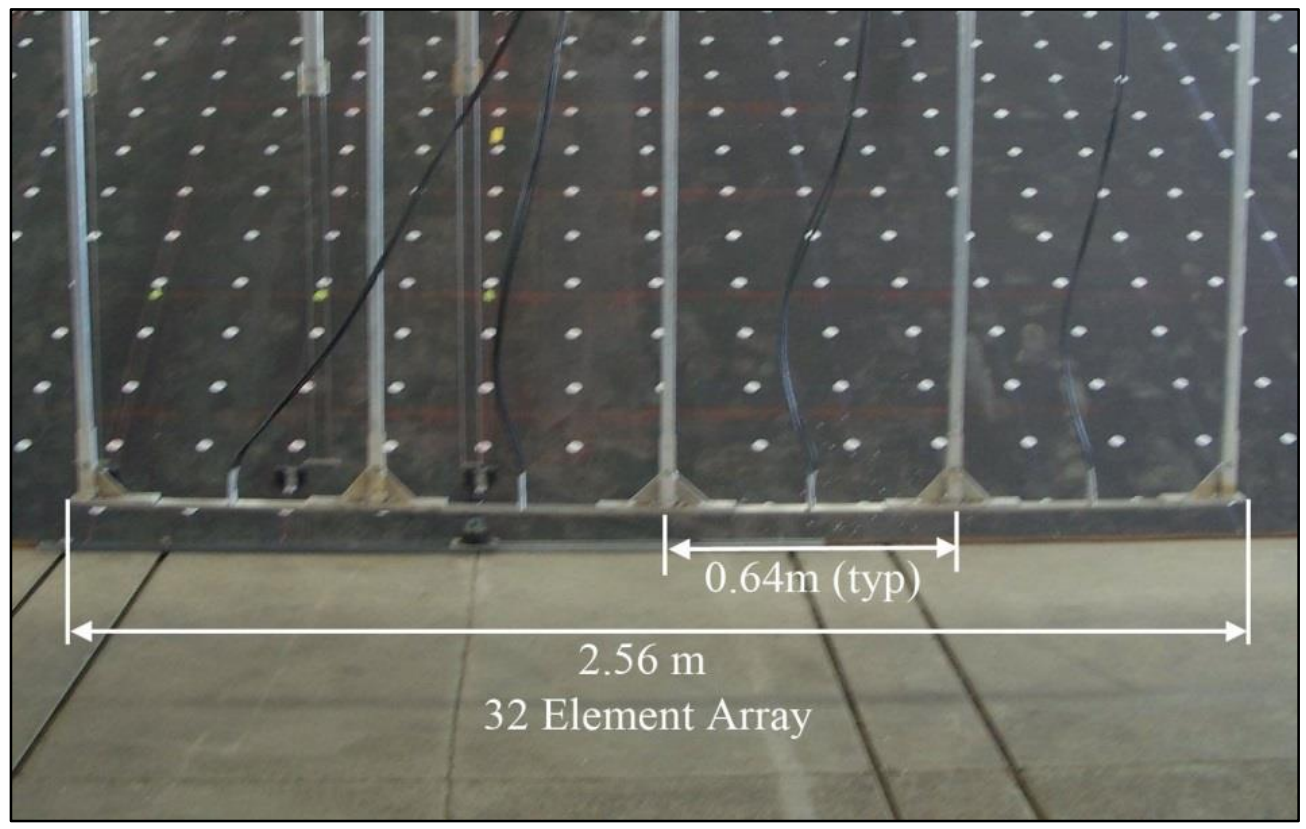

Ripple scanner: The high-frequency acoustic ripple scanners use a fan beam transducer (rotary side scan sonar) and provide an image of the bed typically of the order of 10-30m² (Hay and Wilson 1994; Gallagher et al. 1998; Traykovski et al. 1999; Williams et al. 2000). Ripple length can generally be acquired through analysis of the images, but it is generally not possible to accurately measure the ripple height (Thorne and Hanes 2002). This technology is more commonly used in field applications but could be used to track morphological changes in large basins. The major limitation of this technology is that it requires the instrument to be submerged, and most physical models operate in depths less than $1 \mathrm{~m}$, thus limiting the scanning area of a stationary instrument.

\subsection{Discussion}

Echo sounding technology has been successfully used both in the laboratory and in the field. The suspended sediment concentration, measurement distance, and the maximum beam footprint should be considered when choosing the operating frequency of echo sounding technology. Lower frequencies have reduced attenuation in suspended sediment but have a wider beam footprint. Lower frequencies can also penetrate into the sub-bottom with a reduced resolution. In the laboratory, filter techniques may be required to cope with reflections from the facility walls and bottom. 
Altimeters provide a point measurement and can be used to measure transects in a flume or basin. MTAs can survey larger areas than a single altimeter, which can be helpful quantifying side-wall effects in flume studies or survey larger areas in a basin than single profile transects.

Although ADVs can have bottom profiling capabilities, the main use of them is to measure a point velocity and are not commonly used to measure bathymetric changes beyond the point measurement below the instrument.

Ripple scanners could monitor morphological changes, but the submerged requirement of the instrument makes the instrument impractical in most physical models. Additionally, the limited vertical accuracy of ripple scanners prevents fine-scale bathymetric measurements required in many physical models.

The altimeter, MTA, and ripple scanner use technology that has been scaled for field application. Single-beam echosounders use the same technology as altimeters and are commonly used in hydrographic surveys. Multi-beam echosounders can use the same technology as MTAs and side-scan sonar can use the same technology as ripple scanners. All of these field scaled technologies can be used to measure bathymetry or in assessments of submerged coastal structures. 


\section{Laser Technology}

\subsection{Introduction}

Laser measurement technology has been used in the laboratory and the field to measure bathymetry. This technology is similar to echo sounding but uses light rather than sound. Lasers have a reduced footprint compared to acoustics, which increases the horizontal resolution and can increase accuracy on uneven bathymetry. Additionally, lasers can be used to measure upland topography and bathymetry. Certain wavelengths and intensities of lasers can present an eye hazard, making laser technologies more dangerous than echo sounding.

\subsection{Technology/Methodology}

LIDAR: LIDAR, which stands for light detection and ranging, is a remote sensing technique that uses light in the form of a pulsed laser to measure distances and can be used to measure three-dimensional topographic and bathymetric surfaces. LIDAR systems can be mounted on airborne platforms, terrestrial platforms such as a tripod, or submarine platforms. The USACE Joint Airborne LIDAR Bathymetry Technical Center of Expertise (JALBTCX) operates the Coastal Zone Mapping and Imaging LIDAR (CZMIL) (Tuell et al. 2010), which measures both topography and bathymetry. Commercial terrestrial LIDAR systems typically use 600$1550 \mathrm{~nm}$ lasers for eye safety, which attenuate rapidly in water and are thus limited to measuring upland topography. This causes movable bed physical models to drain the water prior to scanning the bathymetry with commercial terrestrial LIDAR (Bryant and McFall 2016; Smith et al. 2017b, among others).

JALBTCX operates a $532 \mathrm{~nm}$ (blue-green) laser from its CZMIL system (Wozencraft 2010; Tuell et al. 2010) for bathymetric measurements for improved penetration in water. This airborne LIDAR system can provide three-dimensional data of the seafloor that can be used to evaluate nearshore morphology changes, and performs exceptionally well in optically clear environments, and the CZMIL system was designed to work in the wave conditions of the nearshore. Using a $532 \mathrm{~nm}$ laser in confined spaces such as a laboratory generally requires eye protection, depending on the laser's power. 
Stahlmann and Schlurmann (2010) used a $650 \mathrm{~nm}$ (red) laser distance sensor attached to a programmable positioning platform above the flume to measure scour around a pile and create a three-dimensional bathymetric surface. The laser distance sensor operated in submerged conditions, so the flume did not require draining. The advertised vertical resolution of the laser sensor used is $\pm 0.2 \mathrm{~mm}$.

Atkinson and Baldock (2016) coupled a $630 \mathrm{~nm}$ (red) laser distance sensor with a barcode reader to measure the horizontal distance in a flume. The resulting LIDAR system was able to measure subaerial and subaqueous beach profiles with $\pm 2 \mathrm{~mm}$ precision in the vertical and was demonstrated in depths up to $1.6 \mathrm{~m}$. Turbidity in the water prevents measurements, and waiting for sediment to settle may be required with this system. It was also noted that switching from a $630 \mathrm{~nm}$ (red) laser to a $532 \mathrm{~nm}$ (blue-green) laser would improve laser penetration into the water column, allowing for deeper measurements. Bathymetric measurements in most coastal flumes and basins are less than the $1.6 \mathrm{~m}$ depth tested.

ASTRALiTE (https://www.astralitenet/) is a handheld LIDAR bathymetry measurement device that uses a $532 \mathrm{~nm}$ (blue-green) laser to provide point measurements. The ASTRALiTE can be attached to a moving frame for three-dimensional measurements. This LIDAR system was demonstrated using a movable-bed river model at the US Geological Survey, Geomorphology and Sediment Transport Lab in Golden Colorado. The bottom of the channel was mapped with $1 \mathrm{~cm}$ vertical resolution with flowing water. The laser footprint is $5 \mathrm{~cm}$ at $20 \mathrm{~m}$, and the data latency is $0.1 \mathrm{~s}$. The $532 \mathrm{~nm}$ laser has improved water penetration compared to the previously noted red lasers but is more hazardous to the human eye and may require eye protection depending on the laser's power. The vertical resolution of $1 \mathrm{~cm}$ may be inadequate for small-scale movable bed models but may be adequate in large-scale models with large vertical variations or field applications.

The company 3D at Depth (http://3datdepth.com/) has developed several subsea LIDAR systems that are designed for subsea construction, surveys, and inspection, and can be integrated with remotely operated vehicles, autonomous underwater vehicles, surface vessel, and diver systems. Each of its subsea LIDAR systems pulses at 40,000 times per second and can receive over 16 multi-returns per pulse with ranges up to $45 \mathrm{~m}$. The laser wavelength 
is not noted, but the advertised range accuracy of its systems is $\pm 4 \mathrm{~mm}$ or \pm 2 $\mathrm{mm}$, depending on the system.

The company 2GRobtics (https://www.2grobotics.com/) has developed several submersible LIDAR systems that can be used in the laboratory or the field. The ULS-200 can perform mid-range scans (0.36 to $2.5 \mathrm{~m}$ ) with an advertised range resolution of $0.01 \mathrm{~mm}$ at $0.21 \mathrm{~m}, 0.2 \mathrm{~mm}$ at $1.4 \mathrm{~m}$, and $0.6 \mathrm{~mm}$ at $2.5 \mathrm{~m}$. The system uses a $440 \mathrm{~nm}$ wavelength laser, which would have better water penetration but may pose a more significant eye hazard compared to the red $630 \mathrm{~nm}$ wavelength laser.

Laser light sheet and photography: Younkin and Hill (2009) used a planar laser light sheet and camera images to dynamically measure a transect of a scour hole in a flume. The laser light sheet was used to illuminate the measured transect, and a camera recorded the illuminated bathymetry. Only one camera was required, and the image calibration was simplified with this two-dimensional technique. This method could be very useful to dynamically measure bed profile changes along a localized transect, but the profile length will be limited by the length of bathymetry illuminated by the laser light sheet.

\subsection{Discussion}

Lasers retain more accuracy at deeper depths as the laser footprint does not increase as rapidly as acoustic sensors. Laser sensors with $532 \mathrm{~nm}$ (blue-green) frequency penetrate water better than the $630 \mathrm{~nm}$ (red) laser, but with higher eye safety risks. Atkinson and Baldock (2016) showed that a $630 \mathrm{~nm}$ (red) laser could be used to measure bathymetry in a laboratory, but suspended sediment was required to settle before measurements.

The laser sheet with a camera technique could be used to dynamically measure a localized bathymetric transect like a scour hole in a laboratory, but the method is not feasible for field application.

Laser techniques are commonly used in the field to measure bathymetry. The JALBTCX uses LIDAR technology to measure both topography and bathymetry. In the case of laser bathymetric measurements, the eye hazards associated with scaling the field LIDAR system to a confined laboratory environment may require the laser's power to be limited, thus limiting the feasible depth of bathymetric measurements. 


\section{Image Processing Technology}

\subsection{Introduction}

Image processing has been used in the laboratory and the field to measure topography and bathymetry. Different technologies have been developed with varying levels of accuracy. This chapter investigates the different image processing techniques and methods.

\subsection{Technology/Methodology}

Stereophotography: Stereophotograpy is a type of photogrammetry that requires a minimum of two cameras to reconstruct a three-dimensional surface (Porter et al. 2014). This technique has been used in a range of laboratory environments such as subaerial landslide surface reconstruction (McFall 2014; McFall et al. 2018) but has more relevantly been used in laboratory studies to measure bathymetric changes around a pile (Faraci et al. 2000; Baglio et al. 2001; Porter et al. 2014). Baglio et al. 2001 used a laser and diffractive lens to create a grid of points on the sandy bottom, and the dynamic bathymetric measurements were taken using the changes in the spatial position of each point recorded on two cameras. Their system did not account for the refraction of light through the air-glass-water interfaces, thus reducing the accuracy of their results (Porter et al. 2014).

Porter et al. (2014) compared scour measurements near a pile using a marked pile, an altimeter (echosounder), and photogrammetry. A digital projector rather than a laser was used to project a grid of dots on the bathymetric surface. Two different camera arrangements were used for the photogrammetric technique. One setup used a two-camera stereophotograpy setup similar to Baglio et al. 2001, and the second setup used a single underwater camera. The photogrammetry was compared to the measurements of a $1 \mathrm{MHz}$ altimeter with a beam footprint of $8 \mathrm{~mm}$ in diameter at the initial flat-bed surface. The photogrammetry provided more accurate bathymetry than the altimeter, which consistently undermeasured the bathymetry because the altimeter measurement is averaged over the beam footprint. The marked pile provided very accurate scour measurements adjacent to the pile but could not provide threedimensional bathymetric measurements of the scour hole. The main limitation of the photogrammetry technique used was that it required the 
flow in the flume to be stopped for an underwater camera to take photos of the scour hole from several different angles.

The stereophotography technique has subsequently been extended to account for the air-water interface refraction and measure topography and bathymetry of coastal structures at Deltares (Raaijmakers et al. 2012). The extension of stereophotography to account for the air-water interface allows the technique to be insensitive to the actual water level and allows for rapid surface reconstruction with millimeter accuracy without draining the water. This technique does require optically clear water to view the bathymetry or for waves in models to be temporarily stopped for visibility. The synchronized stereophotography camera system and typical target used by Raaijmakers et al. (2012) is shown in Figure 2.

Figure 2. Stereophotography camera system and typical target used by Raaijmakers et al. (2012). The distance between the cameras is known, and the cameras are synchronized.

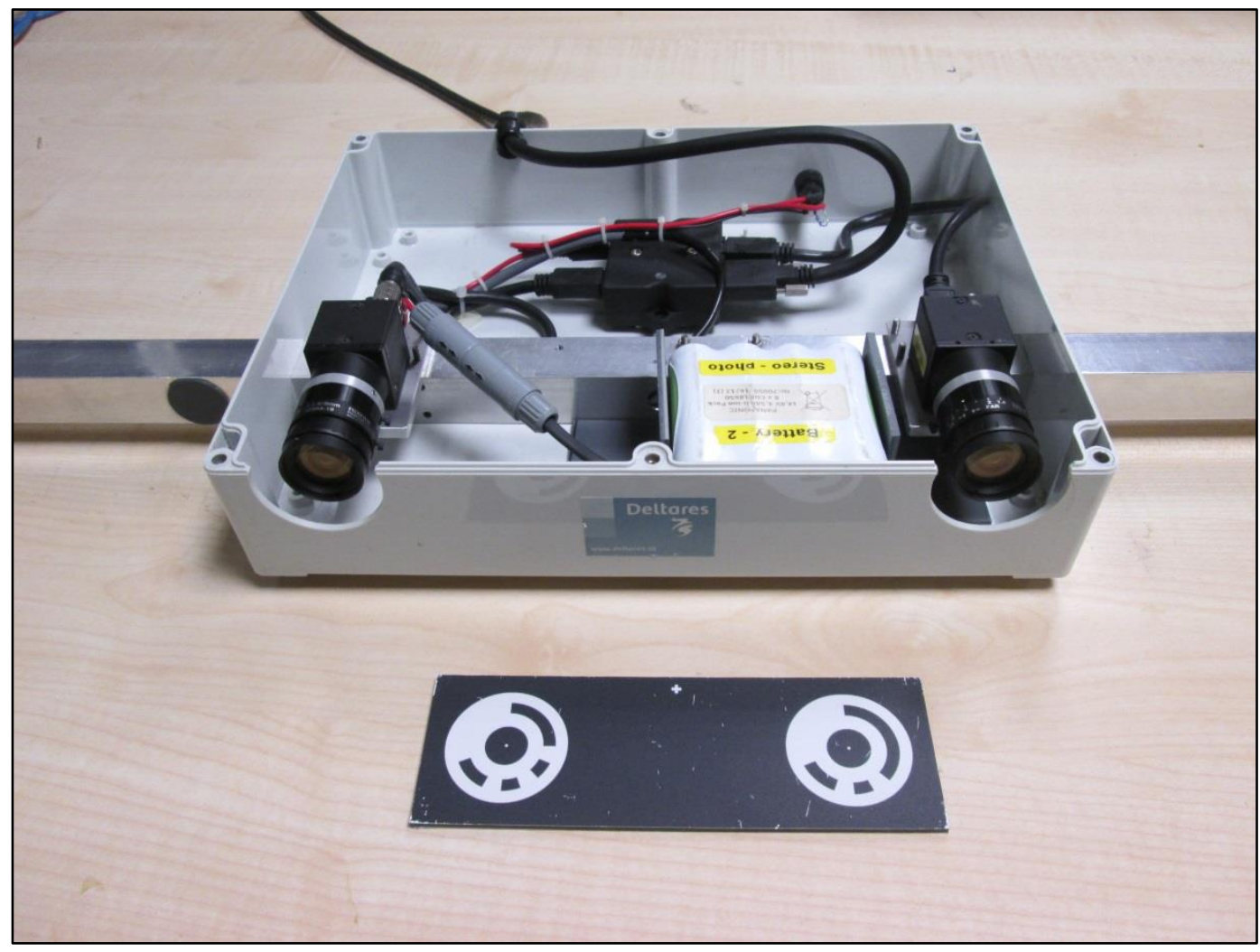


Commercial photogrammetry software and optical bathymetric mapping: Structure-from-Motion (SfM) has become one of the most common and accurate photogrammetric techniques for subaerial surface reconstruction, and it is commercially available. Other photogrammetric methods require the three-dimensional location and position of the camera(s), or the threedimensional location of ground control points to be known for scene triangulation and reconstruction. In contrast, the SfM method solves the camera position and scene geometry simultaneously using a highly redundant bundle adjustment based on matching features in multiple overlapping, offset images (Westoby et al. 2012). SfM has been used in localized applications, similar in scale to laboratory basins, to quantify the volume of dredged sediment in a scow that is emergent from the water ${ }^{1}$, but does not account for the refraction at the air-water interface and is not appropriate for bathymetric measurements. In field studies, SfM has been coupled with optical bathymetric mapping to create a complete subaerial and submarine surface (Javernick et al. 2014). Optical bathymetric mapping works reasonably well for shallow water depths with minimal turbidity and is based on a correlation between the water's depth and color (Winterbottom and Gilvear 1997). This optical bathymetric mapping technique was tested on $1.6 \mathrm{~km}$ stretch of braided river and resulted in a mean error $0.027 \mathrm{~m}$ compared to field measurements with an echo sounder (Javernick et al. 2014).

Coupling SfM and optical bathymetric mapping is most useful in largescale field applications. This technique could be used in the large wave basins with turbid water to link the subaerial beach topography with the underwater beach profile, but the technique requires the waves to be stopped, and the accuracy of the optical bathymetric mapping is inadequate without additional bathymetric measurements for calibration and validation.

cBathy: cBathy is a three-part algorithm that uses recorded images to estimate the bathymetry in the nearshore of coastal environments (Holman et al. 2013). The first phase consists of the frequency dependent characterization of the wave field. The second phase finds the best fit depth for the weighted frequency-wave number pair, and the third phase

\footnotetext{
1 Marshall, J. K., T. L. Welp, J. A. Gough, N. B. Ganesh, T. J. Davidson, and K. L. Garmire. In preparation. Development of a Dredge Scow Measurement System. ERDC/CHL Technical Report. Vicksburg, MS: US Army Engineer Research and Development Center.
} 
uses a Kalman filter to fill gaps in coverage. The remote sensing technique was originally developed with Argus Stations (Holman and Stanley 2007) but has evolved to be used with single stationary cameras and small drones. The algorithm was tested at Duck, NC, using 16 surveys over a 2-year period resulting in an average root-mean-square error of $0.51 \mathrm{~m}$. This technology is developed for the field deployment but could potentially be used in large-scale, movable bed physical models with waves to monitor the morphological evolution between bathymetric surveys. Additionally, wave gauge measurements could be used at point locations for wave spectra characterization.

\subsection{Discussion}

The stereophotography technique has successfully been used in the laboratory with millimeter accuracy. Stereophotography requires optically clear water to see the bathymetry, and waves in the model are required to be temporarily stopped while taking bathymetric measurements. Coupling commercial photogrammetry software with optical bathymetric mapping is appropriate in field studies but is not accurate enough for laboratory studies and would require colored water or turbidity to correlate color to depth. cBathy could potentially be used in the laboratory to monitor morphological changes in wave models between surveys but is not accurate enough to be considered a bathymetric measurement technique.

All three image processing techniques can be used in the field to measure bathymetry. Stereophotography requires optically clear water that is not always present in coastal environments but could potentially be used to reconstruct submerged coastal structures. Optical bathymetric mapping and cBathy were developed in the field and could be used to monitor morphological changes in bathymetry. 


\section{Radar Technology}

\subsection{Introduction}

Radar is an object detection system that uses radio waves to determine range, angle, and velocity of objects. Radar was developed for field application and is commonly used to collect data in the field. Radar can be used to measure wave celerity to infer the bathymetry or can be used to directly measure the bathymetry and potentially the substrate. Similar to the acoustic technology, radar beam size (or spot size) is inversely proportional to the operational frequency (i.e., higher frequencies have a smaller spot size), but higher frequencies attenuate faster in water with high suspended sediment concentrations or high ion concentrations (clay particles or salt water). Lower frequencies have increased sub-bottom penetration but reduced resolution due to the increased beam size.

\subsection{Technology/Methodology}

X-band Radar: X-band radar has been used to measure wave conditions in the field. The wave celerity and period are measured using the modulations in the level of radar backscatter. Similar to cBathy discussion, the bathymetry can be calculated from these wave characteristics using the linear wave dispersion relationship (Bell 1999). Other depth inversion algorithms have been developed with improved accuracy if wave height or wave asymmetry can be determined (Grilli 1998). The data collected by the $\mathrm{X}$-band radar can also be processed using the cBathy algorithm as the data are similar to the visual band in Argus imagery to solve the bathymetric inversion (McNinch 2007).

The radar used to measure the wave characteristics can be stationary (McNinch et al. 2012) or mounted to a vehicle (Brodie 2010). Mounting the radar to a mobile vehicle allows for rapid bathymetric measurements through inversion for large sections of coastline in storm conditions (Spore and Brodie 2017). Bathymetric surveys can be used to validate and calibrate the calculated X-band radar bathymetry (Brutsché et al. 2017).

Using X-band radar to infer the bathymetry has been developed and used extensively in field applications but may work in large-scale physical models if the waves are in the shallow-intermediate wave regime and the radar 
signal is digitized at a high-enough spatial resolution to track morphological changes between direct bathymetric surveys.

Ground penetrating radar (GPR): GPR is not generally designed for water applications, but it has been used in the field to measure bathymetry and the stratigraphic spatial variation in the sea floor (Locker et al. 2017). Generally, the GPR signal attenuates rapidly in mediums with high ionic strength (high salinity or clay). GPR penetrates fresh water and ice well and has been successfully used to map glaciers (Murray et al. 1997) and measure the bathymetry and stratigraphy of a frozen fresh water lake using an $80 \mathrm{MHz}$ center frequency antenna (Haeni et al. 1987).

Compressed high-intensity radar pulse (CHIRP) systems have been used in the ocean for sub-bottom profiling (Wadman and McNinch 2008). Although the CHIRP acronym is used by some vendors, these sub-bottom seismic systems are often acoustic, and chirp refers to the sweep of frequencies used within a given acoustic pulse. These acoustic systems do not use radar in the sense of an electromagnetic signal. Although these CHIRP systems are often acoustic, this technology is kept in the GPR section because of the similar sub-bottom profiling results.

A CHIRP system was used to measure the bathymetry and nearshore sediment thickness at Fire Island, NY, USA (Locker et al. 2017). An Edgetech chirp 512i sub-bottom profiler was installed in a catamaran sled with transducers $\sim 0.91 \mathrm{~m}$ below the water surface, and the sled was towed by a vessel. The CHIRP system used a pulse width of $0.7-12 \mathrm{kHz}$ and a length of $20 \mathrm{~ms}$ to penetrate the sand and maintain vertical resolution. The system was coupled with the Global Positioning System for spatial position information.

GPR has been designed for field applications, and no publications of GPR being used in a hydraulic laboratory setting were located in a recent literature search. Lasers and acoustic sensors are more common remote methods to measure bathymetry in a laboratory setting, but GPR could be applicable for large-scale facilities like the Delta Flume, particularly when the sub-bottom stratigraphy is important. The operating frequency of the GPR is critical to provide adequate resolution and subsurface penetration without contaminating the signal with backscatter from reflections off the facility walls and bottom (Neal 2004). 


\subsection{Discussion}

$\mathrm{X}$-band radar has been used in field applications to calculate the bathymetry by measuring the surface wave conditions and applying a depth inversion algorithm, such as the linear wave dispersion relation. Direct bathymetric measurements using other techniques can be used to validate and calibrate the calculated bathymetric results. This technique has not been used in a laboratory setting but could be used to track morphological changes in large-scale movable bed models between bathymetric measurements. The same cBathy algorithm used by camera systems to calculate the bathymetry can be applied to X-band radar data. The rectification of the $\mathrm{X}$-band radar data is much simpler than the rectification of images from videos or Argus systems, but the collection frequency of most video systems is much higher $(\sim 30 \mathrm{~Hz})$ whereas radar is typically $1-2 \mathrm{~Hz}$.

GPR has not been used in a hydraulic laboratory setting but could be used in large-scale facilities to measure the bathymetry and profile the subbottom stratigraphy. Large-scale hydraulic facilities are better suited for application of GPR compared to confined, smaller facilities to minimize reflections from facility walls and the bottom. Most movable-bed physical models use a constant sediment grain size or use a bimodal distribution of sediment grain sizes. This technique is best suited to situations where there are several different bed materials, such as in physical models studying buried explosive ordinance. This need is rather specific, and although GPR can also measure the bathymetry, less expensive techniques (acoustic, laser, or photogrammetry) can also remotely measure the bathymetry. GPR is only beneficial for very specific scenarios in laboratory settings. 


\section{Conclusions}

Different remote sensing technologies and methods have been investigated to conduct bathymetric measurements in the laboratory settings. The four categories of technology investigated were the following:

1. Echo sounding technology

2. Laser technology

3. Image processing technology

4. Radar technology.

Each technology category has benefits and limitations and can be used to measure bathymetry in the laboratory setting. The recommended technology depends on the type of physical model, optical quality of the water, required accuracy, water depth, suspended sediment concentration, and required horizontal resolution of the bathymetric measurements.

Echo sounding technology requires the instrument to be submerged for bathymetric measurements. The operating frequency of echo sounding technology must be carefully considered as lower frequencies penetrate suspended sediment better than higher frequencies, but lower frequencies have increased beam spreading and a larger beam footprint. This leads to reduced horizontal resolution and decreased accuracy, particularly on uneven bathymetry.

Laser technology has been used to successfully measure bathymetry in a laboratory setting. Lasers have a reduced beam spread compared to echo sounding technology, increasing the horizontal resolution and accuracy on uneven bathymetry. Lasers can attenuate much more rapidly in suspended sediment than echo sounding technology. The $630 \mathrm{~nm}$ (red) laser is commonly used to measure topography but attenuates rapidly in water. The $532 \mathrm{~nm}$ (blue-green) laser penetrates the water better than the $630 \mathrm{~nm}$ (red) laser but has increased eye safety risks. The $630 \mathrm{~nm}$ (red) laser was shown to measure bathymetry in depths up to $1.6 \mathrm{~m}$ in the laboratory, but suspended sediment was required to settle for accurate measurements. Laser technology can penetrate the water surface, which allows for profile measurements to easily translate from the upland topography to the submerged bathymetry. 
Of the image processing techniques discussed, stereophotography is the most applicable technique for measuring the bathymetry in a laboratory setting. The technique requires optically clear water. It has been used to map a scour hole with millimeter accuracy and accounts for the air-water interface to make the technique insensitive to the water level assuming the bathymetry is optically visible. cBathy is an algorithm that is commonly applied to images to calculate the bathymetry and could be used between surveys in large-scale wave models to monitor morphological changes but is not accurate enough to be considered a bathymetric survey technique.

$\mathrm{X}$-band radar can be used to measure wave characteristics to calculate the bathymetry with the same cBathy algorithm that can be applied to images. It is simpler to rectify X-band radar data, but these data cannot be collected at the same frequency as image data. X-band radar is also not accurate enough to be considered a bathymetric survey technique but can monitor morphological changes. GPR has been used in the field to measure bathymetry and sub-bottom stratification. This could be used in larger modeling facilities where sub-bottom stratification is important or in buried explosive ordnance model studies.

All of the categories investigated have been used in field applications to measure bathymetry and submerged coastal structures. Single and multibeam echo sounders are used in hydrographic surveys. LIDAR has been used along the entire US coastline to measure topography and bathymetry through the JALBTCX using the CZMIL system. The depth of the measured bathymetry is dependent on the water clarity. Optical bathymetric mapping has successfully been used to map the bathymetry of rivers. This method uses a correlation between water color and depth to estimate the bathymetry. cBathy was developed in the field to measure bathymetric changes using wave patterns. This technique is particularly helpful to monitor morphological changes in the coastal nearshore. 


\section{References}

Atkinson, A., and T. E. Baldock. 2016. "A High-Resolution Sub-Aerial and Sub-Aqueous Laser Based Laboratory Beach Profile Measurement System.” Coastal Engineering 107: 28-33.

Baglio, S., C. Faraci, E. Foti. and R. Musumeci. 2001. "Measurements of the 3-D Scour Process around a Pile in an Oscillating Flow through a Stereo Vision Approach." Measurement 30(2): 145-160.

Baldock, T. E., J. A. Alsina, I. Caceres, D. Vicinanza, P. Contestabile, H. Power, and A. Sanchez-Arcilla. 2011. "Large-Scale Experiments on Beach Profile Evolution and Surf and Swash Zone Sediment Transport Induced by Long Waves, Wave Groups and Random Waves." Coastal Engineering 58(2): 214-227.

Bell, P. S. 1999. "Shallow Water Bathymetry Derived from an Analysis of X-band Marine Radar Images of Waves." Coastal Engineering 37(3-4): 513-527.

Bell, P., P. Thorne, and J. Williams. 1998. "Acoustic Measurements of Sand Ripple Profile Evolution under Controlled Wave Conditions." Proceedings of the Fourth

European Conference on Underwater Acoustics, held in Rome, Vol. 1, September 21-25, 1998, 353-358.

Brodie, K. L. 2010. Observations of Storm Morphodynamics Using Coastal Lidar and Radar Imaging System (CLARIS).” PhD dissertation. William and Mary: School of Marine Science.

Brutsché, K. E., B. C. McFall, H. Li, J. E. McNinch, J. D. Ousley, J. A. Engle, and C. K. Maglio. 2017. "Strategic Nearshore Placement of Dredged Sediment at Vilano Beach, Florida." Shore \& Beach 85(3): 77-84.

Bryant, D. B., and B. C. McFall. 2016. "Transport of Nearshore Dredge Material Berm." In Proceedings of CoastLab 2016, Ottawa, Canada, 10-13 May 2016.

Ciavola, P., D. Vicinanza, F. Aristodemo, and P. Contestabile. 2011. "Large-Scale Morphodynamic Experiments on a Beach Drainage System." Journal of Hydraulic Research 49(4): 523-528.

Coleman, S. E., C. S. Lauchlan, and B. W. Melville. 2003. "Clear-Water Scour Development at Bridge Abutments." Journal of Hydraulic Research 41(5): 521531.

Dingler, J. R., J. C. Boylls, and R. L. Lowe. 1977. "A High-Frequency Sonar for Profiling Small-Scale Subaqueous Bedforms.” Marine Geology 24(4): 279-288.

Faraci, C., E. Foti, and S. Baglio. 2000. "Measurements of Sandy Bed Scour Processes in an Oscillating Flow by Using Structured Light." Measurement 28(3): 159-174.

Friedrich, H., B. W. Melville, S. E. Coleman, V. I. Nikora, and T. M. Clunie. 2005. "ThreeDimensional Measurement of Laboratory Submerged Bed Forms Using Moving Probes." In Proceedings of XXXI International Association of Hydraulic Engineering and Research Congress, 396-404. 
Fugate, D. C., and C. T. Friedrichs. 2002. "Determining Concentration and Fall Velocity of Estuarine Particle Populations Using ADV, OBS and LISST." Continental Shelf Research 22(11-13): 1867-1886.

Gallagher, E. L., S. Elgar, and E. B. Thornton. 1998. "Megaripple Migration in a Natural Surf Zone." Nature 394(6689) : 165-168.

Greenwood, B., R. G. Richards, and R. W. Brander. 1993. "Acoustic Imaging of Sea-Bed Geometry: A High Resolution Remote Tracking Sonar (HRRTS II).” Marine Geology 112(1-4): 207-218.

Grilli, S. T. 1998. "Depth Inversion in Shallow Water Based on Nonlinear Properties of Shoaling Periodic Waves." Coastal Engineering 35: 185-209.

Haeni, F. P., D. K. McKeegan, and D. R. Capron. 1987. "Ground-Penetrating Radar Study of the Thickness and Extent of Sediments beneath Silver Lake, Berlin and Meriden, Connecticut.” US Geological Survey Water Resources Investigation Report 85-4108. Reston, VA.

Hay, A. E., and D. J. Wilson. 1994. "Rotary Sidescan Images of Nearshore Bedform Evolution during a Storm." Marine Geology 119(1-2) : 57-65.

Holman, R. A., and J. Stanley. 2007. "The History and Technical Capabilities of Argus." Coastal Engineering 54(6-7): 477-491.

Holman, R., N. Plant, and T. Holland. 2013. "cBathy: A Robust Algorithm for Estimating Nearshore Bathymetry.” Journal of Geophysical Research: Oceans 118(5): 25952609.

Javernick, L., J. Brasington, and B. Caruso. 2014. "Modeling the Topography of Shallow Braided Rivers Using Structure-from-Motion Photogrammetry." Geomorphology 213: 166-182.

Jetté, C. D., and D. M. Hanes. 1997. "High-Resolution Sea-Bed Imaging: An Acoustic Multiple Transducer Array." Measurement Science and Technology 8(7): 787792.

Locker, S. D., J. L. Miselis, N. A. Buster, C. J. Hapke, H. M. Wadman, J. E. McNinch, A. S. Forde, and C. A. Stalk. 2017. Nearshore Sediment Thickness, Fire Island, New York. US Geological Survey Open-File Report 2017-1024. Reston, VA.

McFall, B. C. 2014. Physical Modeling of Landslide Generated Tsunamis in Various Scenarios from Fjords to Conical Islands. PhD dissertation. Atlanta, GA: Georgia Institute of Technology.

McFall, B. C., F. Mohammed, H. M. Fritz, and Y. Liu. 2018. "Laboratory Experiments on Three-Dimensional Deformable Granular Landslides on Planar and Conical Slopes." Landslides 15: 1713_1730. doi: 10.1007/s10346-018-0984-2.

McGovern, D. J., S. Ilic, A. M. Folkard, S. J. McLelland, and B. J. Murphy. 2012. "Evolution of Local Scour Around a Collared Monopole through Tidal Cycles." 33rd International Conference on Coastal Engineering, Santander, Spain. 
McNinch, J. E. 2007. "Bar and Swash Imaging Radar (BASIR): A Mobile X-band Radar Designed for Mapping Nearshore Sand Bars and Swash-Defined Shorelines over Large Distances." Journal of Coastal Research 23(1): 59-74.

McNinch, J. E., K. L. Brodie, and R. K. Slocum. 2012. "Radar Inlet Observing System (RIOS): Continuous Remote Sensing of Waves, Currents, and Bathymetry at Tidal Inlets.” In Oceans 2012, 11-19 October 2012, Hampton Roads, VA.

Mohammed, F. 2010. Physical Modeling of Tsunamis Generated by Three-Dimensional Deformable Granular Landslides. PhD dissertation. Georgia Institute of Technology.https://doi.org/10.1029/2011JC007850

Murray, T., D. L. Gooch, and G. W. Stuart. 1997. "Structures within the Surge Front at Bakaninbreen, Svalbard, Using Ground-Penetrating Radar.” Annals of Glaciology 24: 122-129.

Neal, A. 2004. "Ground-Penetrating Radar and Its Use in Sedimentology: Principles, Problems and Progress." Earth-Science Reviews 66(3-4): 261-330.

Perkey, D. W., and H. M. Wadman. 2014. Field Feasibility Study on the Use of Existing Commercially Available Instrumentation to Detect Fine-Scale ( $\leq 1 \mathrm{~mm})$ Bottom Elevation Changes: Currituck Sound, North Carolina. ERDC TN-DOER-D17. Vicksburg, MS: US Army Engineer Research and Development Center.

Porter, K., R. Simons, and J. Harris. 2014. "Comparison of Three Techniques for Scour Depth Measurement: Photogrammetry, Echosounder Profiling and a Calibrated Pile." Coastal Engineering Proceedings 34: 64.

Raaijmakers, T., F. Liefhebber, B. Hofland, and P. Meys. 2012. "Mapping of 3DBathymetries and Structures Using Stereophotography through an Air-WaterInterface." Proceedings of Coastlab 12, 390-399.

Smith, E. R., F. D'Alessandro, G. R. Tomasicchio, and J. Z. Gailani. 2017a. "Nearshore Placement of a Sand Dredged Mound." Coastal Engineering 126: 1-10.

Smith, E. R., M. C. Mohr, and S. A. Chader. 2017b. "Laboratory Experiments on Beach Change Due to Nearshore Mound Placement." Coastal Engineering 121: 119-128.

Spore, N. J., and K. L. Brodie. 2017. Collection, Processing and Accuracy of Mobile Terrestrial Lidar Survey Data in the Coastal Environment. ERDC/CHL TR-17-5. Vicksburg, MS: US Army Engineer Research and Development Center.

Stahlmann, A., and T. Schlurmann. 2010. "Physical Modeling of Scour around Tripod Foundation Structures for Offshore Wind Energy Converters.” In Proceedings of the Coastal Engineering Conference, 2010.

Thorne, P. D., and D. M. Hanes. 2002. "A Review of Acoustic Measurement of SmallScale Sediment Processes.” Continental Shelf Research 22(4): 603-632.

Traykovski, P., R. Geyer, and C. Sommerfield. 2004. "Rapid Sediment Deposition and Fine-Scale Strata Formation in the Hudson Estuary.” Journal of Geophysical Research: Earth Surface 109(F2). 
Traykovski, P., A. E. Hay, J. D. Irish, and J. F. Lynch. 1999. "Geometry, Migration, and Evolution of Wave Orbital Ripples at LEO-15.” Journal of Geophysical Research: Oceans 104(C1): 1505-1524.

Tuell, G., K. Barbor, and J. Wozencraft. 2010. "Overview of the Coastal Zone Mapping and Imaging Lidar (CZMIL): A New Multisensor Airborne Mapping System for the US Army Corps of Engineers." In Algorithms and Technologies for Multispectral, Hyperspectral, and Ultraspectral Imagery XVI (Vol. 7695). International Society for Optics and Photonics.

Van Gent, M. R. A. 2015. "The New Delta Flume for Large-Scale Physical Model Testing." In Proceedings of the $36^{\text {th }}$ IAHR World Congress, The Hague, the Netherlands.

Vincent, C. E., and P. D. Osborne. 1993. "Bedform Dimensions and Migration Rates under Shoaling and Breaking Waves.” Continental Shelf Research 13(11): 12671280 .

Wadman, H. M., and J. E. McNinch. 2008. "Stratigraphic Spatial Variation on the Inner Shelf of a High-Yield River, Waiapu River, New Zealand: Implications for FineSediment Dispersal and Preservation." Continental Shelf Research 28(7): 865886.

Westoby, M. J., J. Brasington, N. F. Glasser, M. J. Hambrey, and J. M. Reynolds. 2012. "Structure-from-Motion Photogrammetry: A Low-Cost, Effective Tool for Geoscience Applications.” Geomorphology 179: 300-314.

Williams, J. J., P. S. Bell, P. D. Thorne, K. Trouw, P. J. Hardcastle, and J. D. Humphery. 2000. "Observed and Predicted Vertical Suspended Sediment Concentration Profiles and Bedforms in Oscillatory-Only Flow." Journal of Coastal Research 16(3): 698-708.

Winterbottom, S. J., and D. J. Gilvear. 1997. "Quantification of Channel Bed Morphology in Gravel-Bed Rivers Using Airborne Multispectral Imagery and Aerial Photography." River Research and Applications 13(6): 489-499.

Wozencraft, J. 2010. "Requirements for the Coastal Zone Mapping and Imaging Lidar." In Algorithms and Technologies for Multispectral, Hyperspectral, and Ultraspectral Imagery XVI (Vol. 7695). International Society for Optics and Photonics.

Younkin, B. D., and D. F. Hill. 2009. "Rapid Profiling of an Evolving Bed Form Using Planar Laser Sheet Illumination.” Journal of Hydraulic Engineering 135(10): $852-85$. 


\section{Unit Conversion Factors}

\begin{tabular}{|c|c|c|}
\hline Multiply & By & To Obtain \\
\hline cubic meters & 1.30795 & cubic yards \\
\hline meters & 3.28084 & feet \\
\hline inches & 0.0254 & meters \\
\hline microns & $1.0 \mathrm{E}-06$ & meters \\
\hline miles (US statute) & 1609.347 & meters \\
\hline kilometers & 0.621371 & Miles \\
\hline
\end{tabular}




\section{Acronyms and Abbreviations}

$\begin{array}{ll}\text { ADV } & \text { acoustic Doppler velocimeter } \\ \text { AWFC } & \text { Army Warfighting Challenges } \\ \text { CHIRP } & \text { compressed high intensity radar pulse } \\ \text { CZMIL } & \text { Coastal Zone Mapping and Imaging LIDAR } \\ \text { GPR } & \text { ground penetrating radar } \\ \text { JALBTCX } & \text { Joint Airborne LIDAR Bathymetry Technical Center of Expertise } \\ \text { MTA } & \text { multiple transducer array } \\ \text { SfM } & \text { Structure-from-Motion }\end{array}$




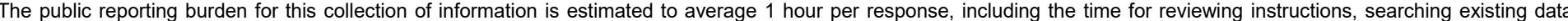

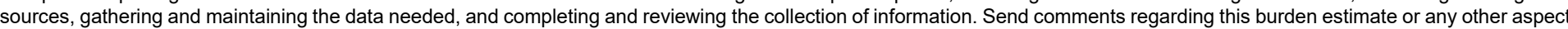

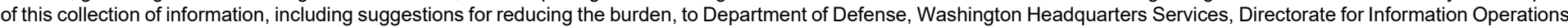

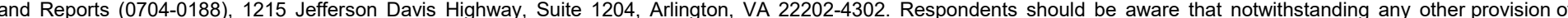
law, no person shall be subject to any penalty for failing to comply with a collection of information if it does not display a currently valid OMB control number. PLEASE DO NOT RETURN YOUR FORM TO THE ABOVE ADDRESS.

\begin{tabular}{l|l|l}
$\begin{array}{l}\text { 1. REPORT DATE } \\
\text { April } 2020\end{array}$ & $\begin{array}{l}\text { 2. REPORT TYPE } \\
\text { Final Report }\end{array}$ & 3. DATES COVERED (FrOm - To)
\end{tabular}

\section{TITLE AND SUBTITLE}

Investigation into Laboratory Bathymetric Measurement Techniques 5a. CONTRACT NUMBER

5b. GRANT NUMBER

5c. PROGRAM ELEMENT NUMBER

6. AUTHOR(S)

Brian C. McFall and Guido Wolters 5d. PROJECT NUMBER

5e. TASK NUMBER

5f. WORK UNIT NUMBER

8. PERFORMING ORGANIZATION REPORT NUMBER

Rotterdamsweg 185

2629HD, Delft, The Netherlands
Coastal and Hydraulics Laboratory

US Army Engineer Research and Development Center

3909 Halls Ferry Road

Vicksburg, MS 39180-6199

\section{SPONSORING/MONITORING AGENCY NAME(S) AND ADDRESS(ES)}

DASA DEC DDODDAC W81MR5

\section{OA-22 HQ}

Arlington, VA 22202

12. DISTRIBUTION/AVAILABILITY STATEMENT

Approved for public release; distribution is unlimited.

\section{SUPPLEMENTARY NOTES}

MIPR 11101100

\section{ABSTRACT}

There is no universally accepted way to accurately and efficiently measure bathymetry in laboratory hydraulic models. Remote sensing techniques can measure bathymetry without making contact with the model, and some remote sensing techniques can measure the bathymetry in laboratory models without draining the water. The four categories of remote sensing technology investigated in this report are echo sounding technology, laser technology, image processing technology, and radar technology. The technology of each category has strengths and limitations, but can be used in the laboratory to measure bathymetry. Echo sounding technology works well in environments with suspended sediment, but the accuracy is reduced by large beam footprints. Laser technology does not perform as well with suspended sediment but can provide high-accuracy bathymetric measurements. Stereophotography, discussed in the image processing technology section, requires optically clear water and can provide very accurate bathymetric mapping. Radar technology can be very helpful when sub-bottom stratigraphy is important. Technology from each of the categories has been scaled for field application to measure bathymetry and submerged coastal structures.

\section{SUBJECT TERMS}

Echo sounding_Evaluation, Hydraulic models, Hydrographic surveying, Optical radar-Evaluation, Photography, Stereoscopic_Evaluation, Radar-Evaluation, Remote sensing

\section{SECURITY CLASSIFICATION OF:}

a. REPORT

Unclassified

\section{b. ABSTRACT}

Unclassified

\section{c. THIS PAGE}

Unclassified
17. LIMITATION OF ABSTRACT

SAR
18. NUMBER 19a. NAME OF RESPONSIBLE PERSON OF PAGES

32
Bryan C. McFall

19b. TELEPHONE NUMBER (Include area code) 601-634-6015 